units and was too large and consistent to be explained by preventive surgery such as coronary artery bypass grafts. A critical examination of the time trends in the use of beta-blocking drugs for the treatment of angina or hypertension might be worth while. The disproportionate decline in the death rates in the youngest age groups in both men and women might be related to either better access to or a greater benefit from medical care. This might apply not only to the management of acute myocardial infarction but to treatment and counselling after infarction (that is, use of beta-blockers and advice on smoking). A change in the natural history of ischaemic heart disease such that it became a "milder" disease might provide an explanation, but why this happened so much later in the United Kingdom than in the USA and Australia would need to be established. A more detailed examination of the changes in lifestyle and medical practice was beyond the scope of this report.

A decline in the rate of death from ischaemic heart disease is thus now apparent; it has many consistencies with changes in fat intake but fewer with changes in smoking habits that have occurred in the UK. If this is the start of a continuing decline in the rate of death from this disease in this country a case may be made for detailed examination of changes in lifestyle and medical practice on a prospective basis to try to find the explanation.
We are grateful to the Tobacco Advisory Council for making available the data on smoking habits collected by Research Services Ltd.

\section{References}

1 Levy RI. Declining mortality in coronary heart disease. Arteriosclerosis $1981 ; 1: 312-25$.

2 Florey CduV, Melia RJW, Darby SC. Changing mortality from ischaemic heart disease in Great Britain 1968-76. Br Med f 1978;i:635-7.

${ }^{3}$ Office of Population Censuses and Surveys. Mortality statistics (cause) England and Wales, 1980. London: HMSO, 1982.

4 Office of Population Censuses and Surveys. Mortality statistics, England and Wales, 1968-79. London: HMSO, 1970-81.

${ }^{5}$ Registrar General for Scotland. Annual report, 1968-80. Edinburgh HMSO, 1969-81.

${ }^{6}$ Ministry of Agriculture, Fisheries and Food (National Food Survey Committee). Household food consumption and expenditure, 1968-79. London: HMSO, 1970-81.

${ }^{7}$ Lee PN, ed. Statistics of smoking in the United Kingdom. 7th ed. (Research paper No 1.) London: Tobacco Research Council, 1976.

* Office of Population Censuses and Surveys. General household survey, 1972 London: HMSO, 1975.

9 Office of Population Censuses and Surveys. General household survey, 1980 London: HMSO, 1982.

\title{
Neurological effects of recombinant human interferon
}

\author{
HOWARD SMEDLEY, MAUREEN KATRAK, KAROL SIKORA, TERENCE WHEELER
}

\begin{abstract}
Ten women with advanced locally recurrent breast cancer who had failed to respond to radiation and hormonal and cytotoxic agents were given up to 12 weeks of recombinant leucocyte interferon $20 \times 10^{6} \mathrm{U} / \mathrm{m}^{2}$ daily or $50 \times 10^{6} \mathrm{U} / \mathrm{m}^{2}$ three times a week. Within one hour of administration influenza-like symptoms began, which one week later were superseded by lethargy, anorexia, and nausea, with a consequent loss of weight in most patients. Other side effects included profound somnolence, confusion, paraesthesia, and (in one patient) signs of an upper motor neurone lesion in the legs. All these effects together with increased slow wave activity in electroencephalograms from all patients during treatment disappeared when interferon was withdrawn and did not recur on reintroducing the drug at a lower dosage.

Studies are continuing to determine the mechanisms of these effects.
\end{abstract}

\footnotetext{
Ludwig Institute for Cancer Research, Addenbrooke's Hospital, Cambridge

HOWARD SMEDLEY, MB, FRCR, senior clinical scientist and honorary senior registrar

MAUREEN KATRAK, SRN, clinical research sister

KAROL SIKORA, MRCP, FRCR, director and honorary consultant in radiotherapy and oncology
}

Department of Radiotherapy, Addenbrooke's Hospital, Cambridge TERENCE WHEELER, FRCR, consultant in radiotherapy and oncology

\section{Introduction}

We are conducting a clinical trial to study the efficacy and safety of highly purified human leucocyte $A$ interferon produced by recombinant DNA technology ${ }^{1}$ in patients with advanced breast cancer. We report here a previously undescribed complication of interferon-namely, dose dependent, reversible central nervous system toxicity.

\section{Patients and results}

All the patients studied had advanced locally recurrent breast cancer which had failed to respond to conventional radiation and hormonal and cytotoxic treatment. Recombinant leucocyte interferon (Hoffmann La Roche) was administered intramuscularly in a dose of either $20 \times 10^{6} \mathrm{U} / \mathrm{m}^{2}$ daily or $50 \times 10^{6} \mathrm{U} / \mathrm{m}^{2}$ three times a week, both regimens being continued for up to 12 weeks. At the time of this report 10 patients had been studied (table).

After initiation of interferon treatment a predictable pattern of side effects common to all patients occurred. Within one hour of injection fever of up to $40^{\circ} \mathrm{C}$ was noted, which could be subsequently successfully prevented with paracetamol $1 \mathrm{~g}$ four times a day. Paracetamol was also effective for headache and myalgia, which were also common during the first four days of treatmen:. No patients developed any immediate anaphylactic reactions, nor was there any change in blood pressure or other vital signs after injection of interferon. Tachyphylaxis against the influenza-like symptoms rapidly developed over the first week, but at one week these side effects were superseded by lethargy and anorexia. Anorexia was often accompanied by nausea but only occasionally by vomiting; it was enough to cause four patients to refuse food altogether for periods of up to one week, with a subsequent fall in weight of greater than $10 \%$ of original body weight. A transient fall in the total white cell and platelet counts was observed but in no patient was this severe enough to warrant withdrawal of treatment. Renal function remained unaltered. Liver function tests showed 
temporary rises in serum alanine aminotransferase activity without any alteration in the bilirubin concentration.

At the doses given six of the 10 patients developed profound lethargy and somnolence by the third week of treatment, causing them to spend up to 20 hours a day asleep and consequently to refuse to take any form of nourishment. This resulted in appreciable weight loss. Five patients developed frank confusion, loss of concentration, and expressive dysphasia. Two patients developed peripheral paraesthesia and one developed signs of an upper motor neurone lesion in the legs. All patients returned to normal within seven to 10 days of withdrawal of interferon and subsequently tolerated the reintroduction of interferon at a reduced dose.

Investigation of the first patient to develop these effects showed no evidence of intracranial metastases to account for the symptoms. An electroencephalogram taken during the confusional state showed a grossly abnormal pattern with excess of slow wave activity. No baseline tracing had been taken in this patient for comparison. Baseline electroencephalograms were obtained in all subsequent patients admitted to the study, and without exception these were normal

Subsequent electroencephalograms were obtained at four, 12, and 14 weeks. All patients showed abnormal tracings by four weeks of treatment with a diffuse increase in slow wave activity while receiving interferon (figure). One patient developed electrophysiological features in keeping with an early encephalopathy. Repeat electroencephalograms after withdrawal of treatment showed return to normal activity. No patient was found to have intracerebral metastases, which may cause a similar syndrome. Two patients showed regression of observable tumour to more than half its pretreatment size (table).

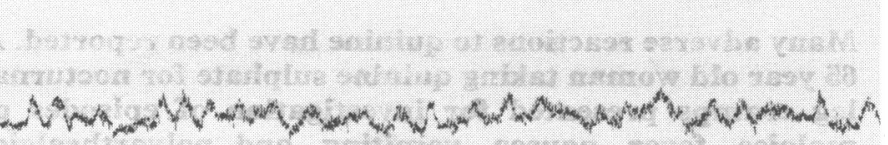

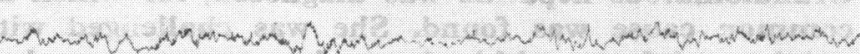

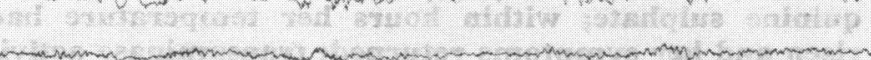
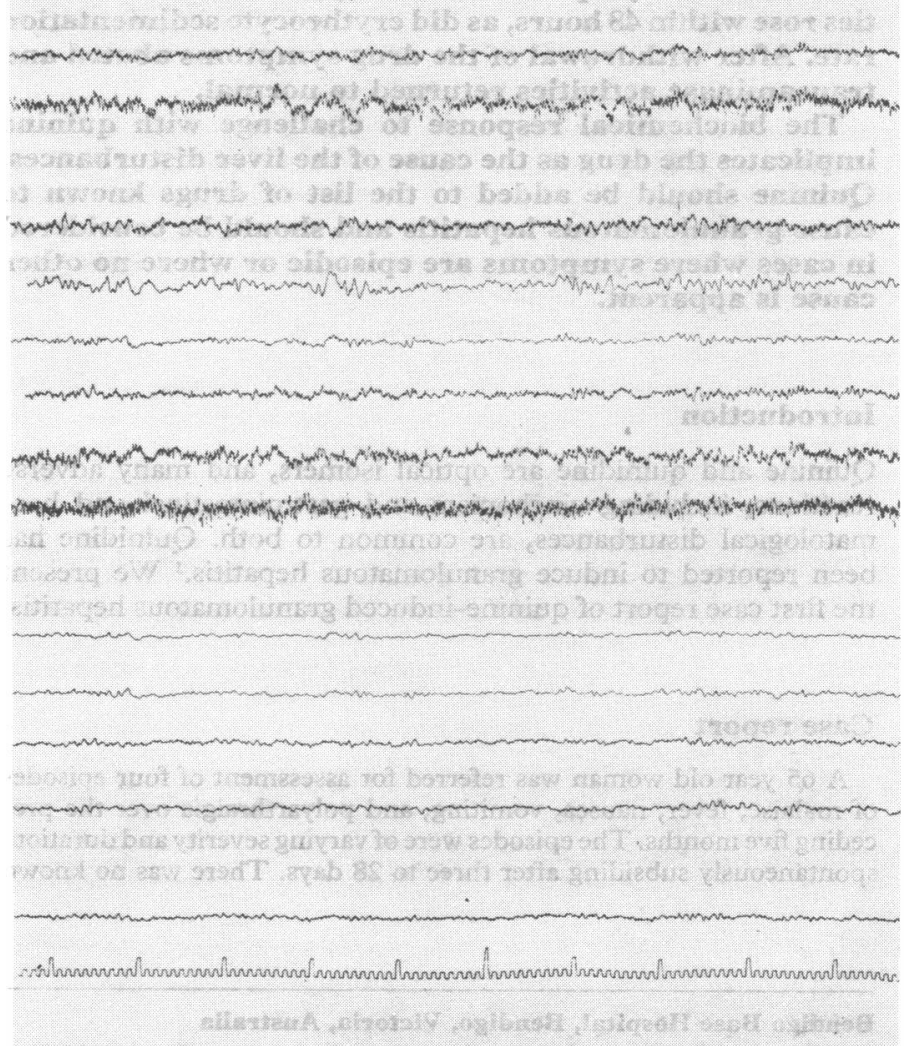

Electroencephalogram showing diffuse increase in slow wave activity during treatment with interferon. 


\section{Discussion}

The clinical findings of reversible central nervous system toxicity with high dose interferon are of considerable interest. In our study they were the major cause of dose limiting toxicity. The preparation used was highly purified, and therefore contaminating molecules were unlikely to be the cause. Previous studies have shown that interferon does not cross the bloodbrain barrier and cannot be identified in cerebrospinal fluid, even in the presence of high circulating blood concentrations. ${ }^{2}$ The mechanism for these effects cannot be explained, and a study is in progress to determine if any subgroups of patients who are at particular risk of developing this distressing syndrome can be identified. It is as yet too early to assess the effectiveness of this interferon in the management of breast cancer.
We thank Drs S De Garis, S Fein, and I Lenox-Smith of HoffmannLa Roche for their helpful advice; Hoffmann-La Roche for providing the interferon; Miss P Hall for electroencephalographic studies; and our colleagues for referring patients for this study.

\section{References}

${ }^{1}$ Maeda S, McCandliss R, Gross M. Construction and identification of bacterial plasmids containing nucleotide sequence of human leucocyte interferon. Proc Natl Acad Sci USA 1980;77:7010-3.

${ }^{2}$ Horning $S$, Levine J, Miller R, Rosenberg S, Merigan T. Clinical and immunologic effects of recombinant leucocyte $A$ interferon in eight patients with advanced cancer. $\mathcal{F} A M A 1982 ; 247: 1718-22$.

\title{
Quinine-induced granulomatous hepatitis
}

\author{
BENNY KATZ, MICHAEL WEETCH, SAIF CHOPRA
}

\begin{abstract}
Many adverse reactions to quinine have been reported. $A$ 65 year old woman taking quinine sulphate for nocturnal leg cramps presented for investigation of episodes of malaise, fever, nausea, vomiting, and polyarthralgia. Granulomatous hepatitis was diagnosed, for which no common cause was found. She was challenged with quinine sulphate; within hours her temperature had risen and her symptoms returned; transaminase activities rose within 48 hours, as did erythrocyte sedimentation rate. After withdrawal of the drug symptoms abated and transaminase activities returned to normal.

The biochemical response to challenge with quinine implicates the drug as the cause of the liver disturbances. Quinine should be added to the list of drugs known to cause granulomatous hepatitis and should be considered in cases where symptoms are episodic or where no other cause is apparent.
\end{abstract}

\section{Introduction}

Quinine and quinidine are optical isomers, and many adverse reactions, including cinchonism and gastrointestinal and haematological disturbances, are common to both. Quinidine has been reported to induce granulomatous hepatitis. ${ }^{1}$ We present the first case report of quinine-induced granulomatous hepatitis.

\section{Case report}

A 65 year old woman was referred for assessment of four episodes of malaise, fever, nausea, vomiting, and polyarthralgia over the preceding five months. The episodes were of varying severity and duration, spontaneously subsiding after three to 28 days. There was no known

Bendigo Base Hospital, Bendigo, Victoria, Australia

BENNY KATZ, MB, Bs, medical registrar (now at Austin Hospital, Heidelberg, Victoria, Australia 3084)

MICHAEL WEETCH, MRCP, FRACP, physician

SAIF CHOPRA, DCP, FRCPA, pathologist contact with infectious disease and no weight loss. She had been taking pindolol and methyclothiazide daily for two years for hypertension, and quinine sulphate, initially prescribed five months before referral, for noctural leg cramps. Apart from a period in hospital 25 years earlier after a severe reaction to penicillin, she had no medical history of note. She rarely consumed alcohol.

On examination she was obese with a blood pressure of $155 / 65$ $\mathrm{mm} \mathrm{Hg}$. She had widespread psoriasis, but no other physical abnormality. Full blood tests showed no abnormality; erythrocyte sedimentation rate was $58 \mathrm{~mm}$ in the first hour. Liver function tests showed a bilirubin concentration of $9 \mu \mathrm{mol} / 1(0.52 \mathrm{mg} / 100 \mathrm{ml}$ ) (normal 0-29 $\mu \mathrm{mol} / 1(0-1.7 \mathrm{mg} / 100 \mathrm{ml})$ ), alkaline phosphatase activity of $306 \mathrm{IU} / 1$ (normal 21-266), aspartate transaminase 129 IU/l (normal 10-30), alanine transaminase $298 \mathrm{IU} / 1$ (normal 6-36), and $\gamma$-glutamyltranspeptidase $238 \mathrm{IU} / 1$ (normal 8-63). Serological tests detected no hepatitis $B$. Other investigations also gave negative results, apart from a positive Mantoux reaction. There was no evidence of active tuberculosis. During the period of investigation the patient felt well, and a spontaneous improvement in the results of liver function tests was noted (fig 1). Percutaneous needle biopsy of the liver showed normal

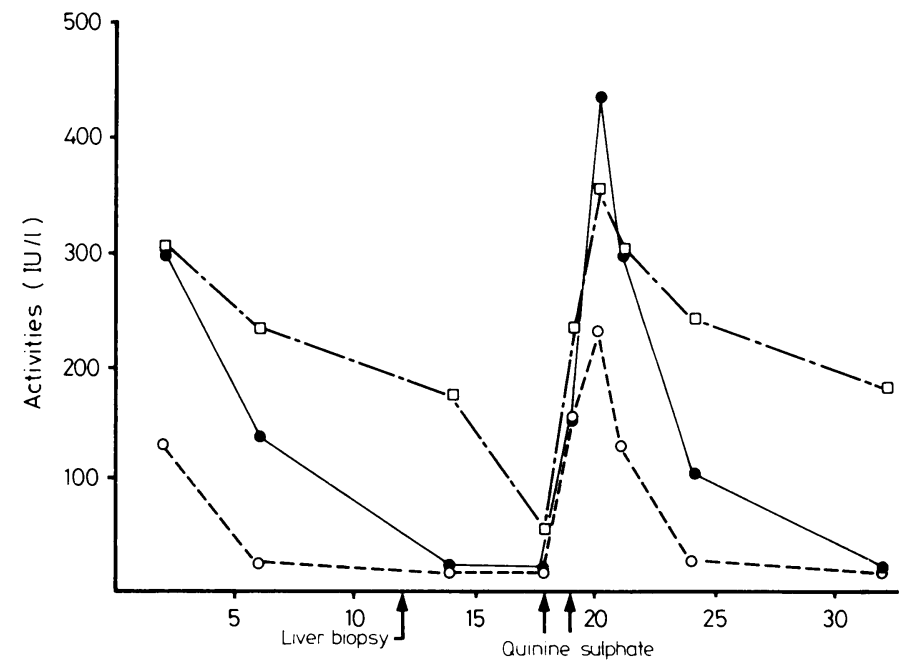

No of days after admission

FIG 1-Results of liver function tests showing a transient rise after challenge with quinine sulphate. Normal values: aspartate transaminase ( $\mathrm{O}--\mathrm{O}$ ) $10 \cdot 30 \mathrm{IU} / 1$, alanine transaminase ( $6.36 \mathrm{IU} / \mathrm{l}$, alkaline phosphatase ( $\square--\square)$ 21-266 IU/1. 